\title{
Letramento e alfabetização: as muitas facetas*
}

\author{
Magda Soares
}

Universidade Federal de Minas Gerais, Centro de Alfabetização, Leitura e Escrita

\section{Introdução}

O título e tema deste texto pretendem ser um contraponto ao título e tema de outro texto de minha autoria, publicado há já quase vinte anos: "As muitas facetas da alfabetização" (Cadernos de Pesquisa, $\mathrm{n}^{\circ} 52$, de fevereiro de 1985). Uso a palavra contraponto para indicar que o que aqui intento fazer é um entrelaçamento dos dois textos, não uma reformulação, muito menos um confronto. É que, relendo, hoje, "As muitas facetas da alfabetização", encontro ali já anunciado, sem que ainda fosse nomeado, o conceito de letramento, que se firmaria posteriormente, e, de forma implícita, as relações entre esse conceito e o conceito de alfabetização; segundo, porque, passados quase vinte anos, as questões ali propostas à reflexão parecem continuar atuais, e grande parte dos problemas ali apontados parece ainda não resolvida. $\mathrm{O}$ contraponto que pretendo desenvolver é a retomada de

* Trabalho apresentado no GT Alfabetização, Leitura e Escrita, durante a $26^{\text {a }}$ Reunião Anual da ANPEd, realizada em Poços de Caldas, MG, de 5 a 8 de outubro de 2003. conceitos e problemas, buscando identificar sua evolução ao longo das duas últimas décadas, em um movimento que vou propor como sendo de progressiva invenção da palavra e do conceito de letramento, e concomitante desinvenção da alfabetização, resultando na polêmica conjuntura atual que me atrevo a denominar de reinvenção da alfabetização.

Para prevenir sobressaltos, adianto, já neste momento inicial de minhas reflexões, que meu objetivo será defender, numa proposta apenas aparentemente contraditória, a especificidade e, ao mesmo tempo, a indissociabilidade desses dois processos - alfabetização e letramento, tanto na perspectiva teórica quanto na perspectiva da prática pedagógica.

\section{A invenção do letramento ${ }^{1}$}

É curioso que tenha ocorrido em um mesmo momento histórico, em sociedades distanciadas tanto geo-

\footnotetext{
${ }^{1}$ A expressão é inspirada no título do livro de Bernard Lahire:
} L'invention de l' "illettrisme" (1999). Entretanto, é aqui outro o sentido que se pretende dar a "invenção": Lahire usa a palavra 
graficamente quanto socioeconomicamente e culturalmente, a necessidade de reconhecer e nomear práticas sociais de leitura e de escrita mais avançadas e complexas que as práticas do ler e do escrever resultantes da aprendizagem do sistema de escrita. Assim, é em meados dos anos de 1980 que se dá, simultaneamente, a invenção do letramento no Brasil, do illettrisme, na França, da literacia, em Portugal, para nomear fenômenos distintos daquele denominado alfabetização, alphabétisation. Nos Estados Unidos e na Inglaterra, embora a palavra literacy já estivesse dicionarizada desde o final do século XIX, foi também nos anos de 1980 que o fenômeno que ela nomeia, distinto daquele que em língua inglesa se conhece como reading instruction, beginning literacy tornou-se foco de atenção e de discussão nas áreas da educação e da linguagem, o que se evidencia no grande número de artigos e livros voltados para o tema, publicados, a partir desse momento, nesses países, e se operacionalizou nos vários programas, neles desenvolvidos, de avaliação do nível de competências de leitura e de escrita da população; segundo Barton (1994, p. 6), foi nos anos de 1980 que the new field of literacy studies has come into existence. É ainda significativo que date aproximadamente da mesma época (final dos anos de 1970) a proposta da Organização da Nações Unidas para a Educação, a Ciência e a Cultura (UNESCO) de ampliação do conceito de literate para functionally literate, e, portanto, a sugestão de que as avaliações internacionais sobre domínio de competências de leitura e de escrita fossem além do medir apenas a capacidade de saber ler e escrever.

Entretanto, se há coincidência quanto ao momento histórico em que as práticas sociais de leitura e de escrita emergem como questão fundamental em sociedades distanciadas geograficamente, socioeconomicamente e culturalmente, o contexto e as causas

para caracterizar a construção social de um discurso sobre o "illettrisme", discurso que, em seu livro, busca desconstruir; aqui, atribui-se à palavra "invenção" o sentido de criação, descoberta, concepção do fenômeno do letramento. dessa emersão são essencialmente diferentes em países em desenvolvimento, como o Brasil, e em países desenvolvidos, como a França, os Estados Unidos, a Inglaterra. Sem pretender uma discussão mais extensa dessas diferenças, o que ultrapassaria os objetivos e possibilidades deste texto, destaco a diferença fundamental, que está no grau de ênfase posta nas relações entre as práticas sociais de leitura e de escrita e a aprendizagem do sistema de escrita, ou seja, entre o conceito de letramento (illettrisme, literacy) e o conceito de alfabetização (alphabétisation, reading instruction, beginning literacy).

Nos países desenvolvidos, ou do Primeiro Mundo, as práticas sociais de leitura e de escrita assumem a natureza de problema relevante no contexto da constatação de que a população, embora alfabetizada, não dominava as habilidades de leitura e de escrita necessárias para uma participação efetiva e competente nas práticas sociais e profissionais que envolvem a língua escrita. Assim, na França e nos Estados Unidos, para limitar a análise a esses dois países, os problemas de illettrisme, de literacy/illiteracy surgem de forma independente da questão da aprendizagem básica da escrita.

Na França, como esclarece Lahire, em L'invention de l'illettrisme (1999), e Chartier e Hébrard, em capítulo incluído na segunda edição de Discours sur la lecture (2000), o illettrisme - a palavra e o problema que ela nomeia - surge para caracterizar jovens e adultos do chamado Quarto Mundo ${ }^{2}$ que revelam precário domínio das competências de leitura e de escrita, dificultando sua inserção no mundo social e no mundo do trabalho. Partindo do fato de que toda a população independentemente de suas condições socioeconômicas - domina o sistema de escrita, porque passou pela escolarização básica, as discussões sobre o illettrisme se fazem sem relação com a questão do apprendre à

${ }^{2}$ A expressão Quarto Mundo designa a parte da população, nos países do Primeiro Mundo, mais desfavorecida. A expressão é usada também para nomear os países menos avançados, entre os países em desenvolvimento. 
lire et à écrire, expressão com que se denomina a alfabetização escolar, e com a questão da alphabétisation, este termo em geral reservado às ações desenvolvidas junto aos trabalhadores imigrantes, analfabetos na língua francesa (Lahire, 1999, p. 61).

O mesmo ocorre nos Estados Unidos, onde o foco em problemas de literacy/illiteracy emerge, no início dos anos de 1980, como resultado da constatação, feita sobretudo em avaliações realizadas no final dos anos de 1970 e início dos anos de 1980 pela National Assessment of Educational Progress (NAEP), de que jovens graduados na high school não dominavam as habilidades de leitura demandadas em práticas sociais e profissionais que envolvem a escrita (Kirsch \& Jungeblut, 1986, p. 2). Também neste caso as discussões, relatórios, publicações não apontam relações entre as dificuldades no uso da língua escrita e a aprendizagem inicial do sistema de escrita - a reading instruction, ou a emergent literacy, a beginning literacy; assim, Kirsch e Jungeblut, como conclusão da pesquisa sobre habilidades de leitura da população jovem norte-americana, afirmam que o problema não estava na illiteracy (no não saber ler e escrever), mas na literacy (no não-domínio de competências de uso da leitura e da escrita).

Essa autonomização, tanto na França quanto nos Estados Unidos, das questões de letramento em relação às questões de alfabetização não significa que estas últimas não venham sendo, elas também, objeto de discussões, avaliações, críticas. Como se verá adiante, neste texto, tem sido também intensa, nos últimos anos, nesses países, a discussão sobre problemas da aprendizagem inicial da escrita; o que se quer aqui destacar é que os dois problemas - o domínio precário de competências de leitura e de escrita necessárias para a participação em práticas sociais letradas e as dificuldades no processo de aprendizagem do sistema de escrita, ou da tecnologia da escrita - são tratados de forma independente, o que revela o reconhecimento de suas especificidades e uma relação de não-causalidade entre eles.

No Brasil, porém, o movimento se deu, de certa forma, em direção contrária: o despertar para a im- portância e necessidade de habilidades para o uso competente da leitura e da escrita tem sua origem vinculada à aprendizagem inicial da escrita, desenvolvendo-se basicamente a partir de um questionamento do conceito de alfabetização. Assim, ao contrário do que ocorre em países do Primeiro Mundo, como exemplificado com França e Estados Unidos, em que a aprendizagem inicial da leitura e da escrita - a alfabetização, para usar a palavra brasileira - mantém sua especificidade no contexto das discussões sobre problemas de domínio de habilidades de uso da leitura e da escrita - problemas de letramento -, no Brasil os conceitos de alfabetização e letramento se mesclam, se superpõem, freqüentemente se confundem. Esse enraizamento do conceito de letramento no conceito de alfabetização pode ser detectado tomando-se para análise fontes como os censos demográficos, a mídia, a produção acadêmica.

Assim, as alterações no conceito de alfabetização nos censos demográficos, ao longo das décadas, permitem identificar uma progressiva extensão desse conceito. A partir do conceito de alfabetizado, que vigorou até o Censo de 1940, como aquele que declarasse saber ler e escrever, o que era interpretado como capacidade de escrever o próprio nome; passando pelo conceito de alfabetizado como aquele capaz de ler e escrever um bilhete simples, ou seja, capaz de não só saber ler e escrever, mas de já exercer uma prática de leitura e escrita, ainda que bastante trivial, adotado a partir do Censo de 1950; até o momento atual, em que os resultados do Censo têm sido freqüentemente apresentados, sobretudo nos casos das Pesquisas Nacionais por Amostragem de Domicílios (PNAD), pelo critério de anos de escolarização, em função dos quais se caracteriza o nível de alfabetização funcional da população, ficando implícito nesse critério que, após alguns anos de aprendizagem escolar, o indivíduo terá não só aprendido a ler e escrever, mas também a fazer uso da leitura e da escrita, verifica-se uma progressiva, embora cautelosa, extensão do conceito de alfabetização em direção ao conceito de letramento: do saber ler e escrever em direção ao ser capaz de fazer uso da leitura e da escrita. 
O mesmo se verifica quando se observa o tratamento que a mídia dá, particularmente ao longo da última década (anos de 1990), às informações e notícias sobre alfabetização no Brasil. ${ }^{3}$ Já em 1991, a Folha de S. Paulo, ao divulgar resultados do Censo então realizado, após declarar que, pelos dados, apenas $18 \%$ eram analfabetos, acrescenta: "mas o número de desqualificados é muito maior". Desqualificados, segundo a matéria, eram aqueles que, embora declarando saber ler e escrever um bilhete simples, tinham menos de quatro anos de escolarização, sendo, assim, analfabetos funcionais. Durante toda a última década e até hoje a mídia vem usando, em matérias sobre competências de leitura e escrita da população brasileira, termos como semi-analfabetos, iletrados, analfabetos funcionais, ao mesmo tempo que vem sistematicamente criticando as informações sobre índices de alfabetização e analfabetismo que tomam como base apenas o critério censitário de saber ou não saber "ler e escrever um bilhete simples". A mídia vem, pois, assumindo e divulgando um conceito de alfabetização que $o$ aproxima do conceito de letramento.

Interessante é observar que também na produção acadêmica brasileira alfabetização e letramento estão quase sempre associados. Uma das primeiras obras a registrar o termo letramento, Adultos não alfabetizados: o avesso do avesso, de Leda Verdiani Tfouni (1988), aproxima alfabetização e letramento, é verdade que para diferenciar os dois processos, tema a que retorna em livro posterior, em que a aproximação entre os dois conceitos aparece já desde o título: Letramento e alfabetização (1995). Essa mesma aproximação entre os dois conceitos aparece na coletânea organizada por Roxane Rojo, Alfabetização e letramento (1998), em que está também presente a proposta de uma diferenciação entre os dois fenômenos, embora não inteiramente coincidente com a proposta por Leda Verdiani Tfouni. Ângela Kleiman, na coletânea que organiza - Os significados do letramento

\footnotetext{
${ }^{3}$ Uma análise mais detalhada da progressiva ampliação do
} conceito de alfabetização na mídia é apresentada em Soares (2003).
(1995) -, também discute o conceito de letramento tomando como contraponto o conceito de alfabetização, e os dois conceitos se alternam ao longo dos textos da coletânea. No livro Letramento: um tema em três gêneros (1998), procuro conceituar, confrontando-os, os dois processos - alfabetização e letramento. São apenas exemplos que privilegiam as obras mais conhecidas sobre o tema, da tendência predominante na literatura especializada tanto na área das ciências lingüísticas quanto na área da educação: a aproximação, ainda que para propor diferenças, entre letramento e alfabetização, o que tem levado à concepção equivocada de que os dois fenômenos se confundem, e até se fundem. Embora a relação entre alfabetização e letramento seja inegável, além de necessária e até mesmo imperiosa, ela, ainda que focalize diferenças, acaba por diluir a especificidade de cada um dos dois fenômenos, como será discutido posteriormente neste texto.

Em síntese, e para encerrar este tópico, concluise que a invenção do letramento, entre nós, se deu por caminhos diferentes daqueles que explicam a invenção do termo em outros países, como a França e os Estados Unidos. Enquanto nesses outros países a discussão do letramento - illettrisme, literacy e illiteracy - se fez e se faz de forma independente em relação à discussão da alfabetização - apprendre à lire et à écrire, reading instruction, emergent literacy, beginning literacy -, no Brasil a discussão do letramento surge sempre enraizada no conceito de alfabetização, o que tem levado, apesar da diferenciação sempre proposta na produção acadêmica, a uma inadequada e inconveniente fusão dos dois processos, com prevalência do conceito de letramento, por razões que tentarei identificar mais adiante, o que tem conduzido a um certo apagamento da alfabetização que, talvez com algum exagero, denomino desinvenção da alfabetização, de que trato em seguida.

\section{A desinvenção da alfabetização}

O neologismo desinvenção pretende nomear a progressiva perda de especificidade do processo de 
alfabetização que parece vir ocorrendo na escola brasileira ao longo das duas últimas décadas. ${ }^{4}$ Certamente essa perda de especificidade da alfabetização é fator explicativo - evidentemente, não o único, mas talvez um dos mais relevantes - do atual fracasso na aprendizagem e, portanto, também no ensino da língua escrita nas escolas brasileiras, fracasso hoje tão reiterado e amplamente denunciado. É verdade que não se denuncia um fato novo: fracasso em alfabetização nas escolas brasileiras vem ocorrendo insistentemente há muitas décadas; hoje, porém, esse fracasso configurase de forma inusitada. Anteriormente ele se revelava em avaliações internas à escola, sempre concentrado na etapa inicial do ensino fundamental, traduzindose em altos índices de reprovação, repetência, evasão; hoje, o fracasso revela-se em avaliações externas à escola - avaliações estaduais (como o SARESP, o SIMAVE), nacionais (como o SAEB, o ENEM) e até internacionais (como o PISA),$-{ }^{5}$ espraia-se ao longo de todo o ensino fundamental, chegando mesmo ao ensino médio, e se traduz em altos índices de precário ou nulo desempenho em provas de leitura, denunciando grandes contingentes de alunos não alfabetizados ou semi-alfabetizados depois de quatro, seis, oito anos de escolarização. A hipótese aqui levantada é que a perda de especificidade do processo de alfabetização, nas duas últimas décadas, é um, entre os muitos e variados fatores, que pode explicar esta atual "modalidade" de fracasso escolar em alfabetização.

Talvez se possa afirmar que na "modalidade" anterior de fracasso escolar - aquela que se manifestava em altos índices de reprovação e repetência na

\footnotetext{
${ }^{4}$ Convém esclarecer que as reflexões aqui desenvolvidas têm como objeto privilegiado de análise a escola pública.

${ }^{5}$ SARESP - Sistema de Avaliação da Rede Estadual de São Paulo; SIMAVE - Sistema Mineiro de Avaliação da Educação Pública ; SAEB - Sistema Nacional de Avaliação da Educação Básica; ENEM - Exame Nacional do Ensino Médio; PISA - Programa Internacional de Avaliação de Estudantes.
}

etapa inicial do ensino fundamental ${ }^{6}$ - a alfabetização caracterizava-se, ao contrário, por sua excessiva especificidade, entendendo-se por "excessiva especificidade" a autonomização das relações entre o sistema fonológico e o sistema gráfico em relação às demais aprendizagens e comportamentos na área da leitura e da escrita, ou seja, a exclusividade atribuída a apenas uma das facetas da aprendizagem da língua escrita. O que parece ter acontecido, ao longo das duas últimas décadas, é que, em lugar de se fugir a essa "excessiva especificidade", apagou-se a necessária especificidade do processo de alfabetização.

Várias causas podem ser apontadas para essa perda de especificidade do processo de alfabetização; limitando-me às causas de natureza pedagógica, cito, entre outras, a reorganização do tempo escolar com a implantação do sistema de ciclos, que, ao lado dos aspectos positivos que sem dúvida tem, pode trazer e tem trazido - uma diluição ou uma preterição de metas e objetivos a serem atingidos gradativamente ao longo do processo de escolarização; o princípio da progressão continuada, que, mal concebido e mal aplicado, pode resultar em descompromisso com o desenvolvimento gradual e sistemático de habilidades, competências, conhecimentos. Não me detenho, porém, no aprofundamento das relações entre esses aspectos - sistema de ciclos, princípio da progressão continuada - e a perda de especificidade da alfabetização, porque me parece que a causa maior dessa perda de especificidade deve ser buscada em fenômeno mais complexo: a mudança conceitual a respeito da aprendizagem da língua escrita que se difundiu no Brasil a partir de meados dos anos de 1980.

Segundo Gaffney e Anderson (2000, p. 57), as últimas três décadas assistiram a mudanças de para-

${ }^{6}$ É preciso reconhecer que esta modalidade de fracasso escolar aqui caracterizada como anterior continua presente, ainda não superada; o adjetivo anterior é aqui usado apenas para diferenciá-la de uma nova modalidade que se vem revelando nas últimas décadas . 
digmas teóricos no campo da alfabetização que podem ser assim resumidas: um paradigma behaviorista, dominante nos anos de 1960 e 1970, é substituído, nos anos de 1980, por um paradigma cognitivista, que avança, nos anos de 1990, para um paradigma sociocultural. Segundo os mesmos autores, se a transição da teoria behaviorista para a teoria cognitivista representou realmente uma radical mudança de paradigma, a transição da teoria cognitivista para a perspectiva sociocultural pode ser interpretada antes como um aprimoramento do paradigma cognitivista que propriamente como uma mudança paradigmática.

Embora Gaffney e Anderson situem essas mudanças paradigmáticas no contexto norte-americano, pode-se reconhecer as mesmas mudanças no Brasil, aproximadamente no mesmo período; ${ }^{7}$ em relação ao período que aqui interessa, pode-se afirmar que, tal como ocorreu nos Estados Unidos, também no Brasil os anos de 1980 e 1990 assistiram ao domínio hegemônico, na área da alfabetização, do paradigma cognitivista, que aqui se difundiu sob a discutível denominação de construtivismo (posteriormente, socioconstrutivismo). Ao contrário, porém, dos Estados Unidos, em que esse paradigma foi proposto para todo e qualquer conhecimento escolar, tomando como eixo uma nova concepção das relações entre aprendizagem e linguagem, traduzida no movimento que recebeu a denominação de whole language ${ }^{8}$ entre nós ele chegou pela via da alfabetização, através das pesqui-

${ }^{7}$ Gaffney e Anderson identificam as mudanças de paradigma na área da alfabetização, nos Estados Unidos, nas três últimas décadas (1970, 1980 e 1990), analisando relatos de pesquisa publicados nas revistas Reading Research Quarterly (697 artigos) e The Reading Teacher (3.018 artigos), no período de 1966 a 1998. Uma comparação entre os resultados a que chegam esses autores e os resultados da pesquisa sobre o estado do conhecimento a respeito da alfabetização no Brasil, que vem sendo desenvolvida no Centro de Alfabetização, Leitura e Escrita - CEALE, da Faculdade de Educação da UFMG (Soares \& Maciel, 2000), mostram que as mesmas tendências ocorrem também no Brasil.

${ }^{8} \mathrm{~A}$ whole language tem sua origem em um conjunto de princípios teóricos, com raízes basicamente psicolingüísticas, so- sas e estudos sobre a psicogênese da língua escrita, divulgada pela obra e pela atuação formativa de Emilia Ferreiro. ${ }^{9}$

Não é necessário retomar aqui a mudança que representou, para a área da alfabetização, a perspectiva psicogenética: alterou profundamente a concepção do processo de construção da representação da língua escrita, pela criança, que deixa de ser considerada como dependente de estímulos externos para aprender o sistema de escrita - concepção presente nos métodos de alfabetização até então em uso, hoje designados "tradicionais" $-{ }^{10}$ e passa a sujeito ativo

bre a natureza holística da linguagem, da aprendizagem e, conseqüentemente, do ensino, que se difundiu nos Estados Unidos nos anos de 1970, sob a liderança de Kenneth Goodman, tendo se concretizado em proposta pedagógica; embora voltados para todas as áreas do currículo (cf. Smith, Goodman \& Meredith, 1970, uma das primeiras obras sobre os princípios teóricos dessa visão holística), esses princípios ganharam lugar e relevância sobretudo na área do ensino da língua, e particularmente do ensino e aprendizagem da língua escrita, tendo, nesta área, recebido apoio e reforço de Frank Smith e sua teoria psicolingüística do processo de leitura (cf. Smith, 1973 e 1997, para citar uma de suas primeiras obras e uma recente, publicada quase 25 anos depois). A proposta pedagógica da whole language para a alfabetização aproxima-se das que, a partir de meados dos anos de 1980, no Brasil, derivaram dos estudos sobre a psicogênese da língua escrita, de Emilia Ferreiro e Ana Teberosky (1985).

${ }^{9}$ A relação entre a concepção "construtivista" da aprendizagem e a alfabetização foi compreendida de forma tão absoluta no Brasil que se difundiu amplamente o conceito equivocado de que só na fase da aprendizagem da língua escrita poderia um professor ser "construtivista".

${ }^{10}$ Não se atribui, aqui, ao adjetivo "tradicional" o sentido pejorativo que costuma ter; o termo é aqui utilizado para caracterizar, de forma descritiva e não avaliativa, os métodos vigentes até o momento da introdução da perspectiva "construtivista" na área da alfabetização; é preciso lembrar que esses métodos hoje considerados "tradicionais" um dia foram "novos" ou "inovadores" - o tradicional não se esgota no passado, é fruto de um processo permanente que não termina nunca: estamos construindo hoje o "tradicional" de amanhã, quando outros "novos" surgirão. 
capaz de progressivamente (re)construir esse sistema de representação, interagindo com a língua escrita em seus usos e práticas sociais, isto é, interagindo com material "para ler", não com material artificialmente produzido para "aprender a ler"; os chamados prérequisitos para a aprendizagem da escrita, que caracterizariam a criança "pronta" ou "madura" para ser alfabetizada - pressuposto dos métodos "tradicionais" de alfabetização - são negados por uma visão interacionista, que rejeita uma ordem hierárquica de habilidades, afirmando que a aprendizagem se dá por uma progressiva construção do conhecimento, na relação da criança com o objeto "língua escrita"; as dificuldades da criança, no processo de construção do sistema de representação que é a língua escrita - consideradas "deficiências" ou "disfunções", na perspectiva dos métodos "tradicionais" - passam a ser vistas como "erros construtivos", resultado de constantes reestruturações.

Sem negar a incontestável contribuição que essa mudança paradigmática, na área da alfabetização, trouxe para a compreensão da trajetória da criança em direção à descoberta do sistema alfabético, é preciso, entretanto, reconhecer que ela conduziu a alguns equívocos e a falsas inferências, que podem explicar a desinvenção da alfabetização, de que se fala neste tópico - podem explicar a perda de especificidade do processo de alfabetização, proposta anteriormente.

Em primeiro lugar, dirigindo-se o foco para o processo de construção do sistema de escrita pela criança, passou-se a subestimar a natureza do objeto de conhecimento em construção, que é, fundamentalmente, um objeto lingüístico constituído, quer se considere o sistema alfabético quer o sistema ortográfico, de relações convencionais e freqüentemente arbitrárias entre fonemas e grafemas. Em outras palavras, privilegiando a faceta psicológica da alfabetização, obscureceu-se sua faceta lingüística - fonética e fonológica.

Em segundo lugar, derivou-se da concepção construtivista da alfabetização uma falsa inferência, a de que seria incompatível com o paradigma conceitual psicogenético a proposta de métodos de alfabetização.
De certa forma, o fato de que o problema da aprendizagem da leitura e da escrita tenha sido considerado, no quadro dos paradigmas conceituais "tradicionais", como um problema sobretudo metodológico contaminou o conceito de método de alfabetização, atribuindo-lhe uma conotação negativa: é que, quando se fala em "método" de alfabetização, identifica-se, imediatamente, "método" com os tipos "tradicionais" de métodos - sintéticos e analíticos (fônico, silábico, global etc.), como se esses tipos esgotassem todas as alternativas metodológicas para a aprendizagem da leitura e da escrita. Talvez se possa dizer que, para a prática da alfabetização, tinha-se, anteriormente, um método, e nenhuma teoria; com a mudança de concepção sobre o processo de aprendizagem da língua escrita, passou-se a ter uma teoria, e nenhum método.

Acrescente-se a esses equívocos e falsas inferências o também falso pressuposto, decorrente deles e delas, de que apenas através do convívio intenso com o material escrito que circula nas práticas sociais, ou seja, do convívio com a cultura escrita, a criança se alfabetiza. A alfabetização, como processo de aquisição do sistema convencional de uma escrita alfabética e ortográfica, foi, assim, de certa forma obscurecida pelo letramento, porque este acabou por freqüentemente prevalecer sobre aquela, que, como conseqüência, perde sua especificidade.

É preciso, a esta altura, deixar claro que defender a especificidade do processo de alfabetização não significa dissociá-lo do processo de letramento, como se defenderá adiante. Entretanto, o que lamentavelmente parece estar ocorrendo atualmente é que a percepção que se começa a ter, de que, se as crianças estão sendo, de certa forma, letradas na escola, não estão sendo alfabetizadas, parece estar conduzindo à solução de um retorno à alfabetização como processo autônomo, independente do letramento e anterior a ele. É o que estou considerando ser uma reinvenção da alfabetização que, numa afirmação apenas aparentemente contraditória, é, ao mesmo tempo, perigo$s a-$ se representar um retrocesso a paradigmas anteriores, com perda dos avanços e conquistas feitos nas últimas décadas - e necessária - se representar a re- 
cuperação de uma faceta fundamental do processo de ensino e de aprendizagem da língua escrita. É do que se tratará no próximo tópico.

\section{A reinvenção da alfabetização}

Temos usado com frequiência na área da educação a metáfora da "curvatura da vara", a que os americanos preferem a metáfora do "pêndulo", ambas representando a tendência ao raciocínio alternativo: ou isto ou aquilo; se isto, então não aquilo.

A autonomização do processo de alfabetização, em relação ao processo de letramento, para a qual se está tendendo atualmente, pode ser interpretada como a curvatura da vara ou o movimento do pêndulo para o "outro" lado. O "lado" contra o qual essa tendência se levanta, aquele que, de certa forma, dominou o ensino da língua escrita não só no Brasil, mas também em vários outros países, nas últimas décadas, baseia-se numa concepção holística da aprendizagem da língua escrita, de que decorre o princípio de que aprender a ler e a escrever é aprender a construir sentido para e por meio de textos escritos, usando experiências e conhecimentos prévios; no quadro dessa concepção, o sistema grafofônico (as relações fonema-grafema) não é objeto de ensino direto e explícito, pois sua aprendizagem decorreria de forma natural da interação com a língua escrita. É essa concepção e esse princípio que fundamentam a whole language, nos Estados Unidos, e o chamado construtivismo, no Brasil.

Entretanto, resultados de avaliações de níveis de alfabetização da população em processo de escolarização, que se multiplicaram nas duas últimas décadas, no Brasil e em muitos outros países, têm levado a críticas a essa concepção holística da aprendizagem da língua escrita, incidindo essa crítica particularmente na ausência, no quadro dessa concepção, de instrução direta e específica para a aprendizagem do código alfabético e ortográfico. Em países que, tradicionalmente, têm inspirado a educação brasileira - França e Estados Unidos -, essa crítica e recomendações dela decorrentes foram recentemente expressas em docu- mentos oficiais e programas de ensino, de que convém dar rápida notícia, uma vez que o movimento que começa a esboçar-se entre nós nessa mesma direção tem buscado neles (embora não só neles) fundamento e justificação.

Na França, a constatação de dificuldades de leitura e de escrita na população em fase de escolarização levou o Observatório Nacional da Leitura, órgão consultivo do Ministério da Educação Nacional, da Pesquisa e da Tecnologia, a divulgar, no final dos anos de 1990, o documento Apprendre à lire au cycle des apprentissages fondamentaux (Observatoire National de la Lecture, 1998), em que, com apoio em dados de pesquisas sobre a aprendizagem da leitura, afirma-se que o conhecimento do código grafofônico e o domínio dos processos de codificação e decodificação constituem etapa fundamental e indispensável para o acesso à língua escrita, "condition nécessaire, bien que non suffisante, de la comprehénsion des textes" (grifo do original), etapa que não pode ser vencida

[...] sans une instruction explicite, visant d'une part la prise de conscience du fait que la parole peut être décrite comme une séquence linéaire de phonèmes, d'autre part, que les caractères (ou groupes de caractères) alphabétiques représentent les phonèmes. (p. 93)

Nos Estados Unidos, desde o início dos anos de 1990 tem sido intensa a discussão sobre a aprendizagem da língua escrita na escola, discussão que se concentra, sobretudo, em polêmicas que contrapõem a concepção holística - whole language - à concepção grafofônica-phonics. ${ }^{11}$ Em meados dos anos de 1990,

${ }^{11} \mathrm{Na}$ verdade, a discussão, nos Estados Unidos, em torno de teorias e métodos de alfabetização antecede o debate em torno de whole language e phonics, pois ela se vem desenvolvendo desde os anos de 1960, configurando o que a literatura educacional daquele país tem denominando The Reading Wars. Assim, já em 1967 foram realizados dois estudos sobre a alfabetização no país: The cooperative research program in first-grade reading instruction, mais conhecido como first-grade studies (Bond \& Dykstra, 1967/1997) 
a whole language, que vinha tendo grande difusão no país desde meados dos anos de 1980, passou a ser contestada, sobretudo por negar o ensino do sistema alfabético e ortográfico e das relações fonema-grafema de forma direta e explícita. Já em de 1990, a publicação da obra de Marilyn Jager Adams, Beginning to read : thinking and learning about print, levara à substituição da oposição phonics versus whole-word, em torno da qual se desenvolvia, até então, o debate, pela oposição phonics versus whole language. Identificase um paralelo com o que ocorreu no Brasil aproximadamente na mesma época, quando o debate que até então se fazia em torno da oposição entre métodos sintéticos (fônico, silabação) e métodos analíticos (palavração, sentenciação, global) foi suplantado pela introdução da concepção "construtivista" na alfabetização, bastante semelhante à whole language.

Os defensores do ensino direto e explícito das relações fonema-grafema, no processo de alfabetização, nos Estados Unidos, encontraram reforço no relatório produzido, em 2000, pelo National Institute of Child Health and Human Development (NICHD), em resposta à solicitação do Congresso Nacional, alarmado com os baixos níveis de competência em leitura que avaliações estaduais e nacionais de crianças em processo de escolarização vinham denunciando: o National Reading Panel: teaching children to read é um estudo de avaliação e integração das pesquisas existentes no país sobre a alfabetização de crianças,

e Learning to read: the great debate (Chall, 1967); em 1985, foram apresentados os resultados de um outro estudo, o relatório Becoming a nation of readers (Anderson et al., 1985); novo estudo, realizado por Marilyn Jager Adams, foi publicado em 1990, Beginning to read: thinking and learning about print (Adams, 1990); em 1998, novo relatório é publicado: Preventing reading difficulties in young children (Snow, Burns \& Griffin, 1998); o último estudo realizado, aquele que neste texto se comenta, é de 2000, publicado com o título de Report of the National Reading Panel: teaching children to read (National Institute of Child Health and Human Development, 2000). Uma análise e crítica desses relatórios pode ser encontrada em Cowen (2003). com o objetivo de identificar procedimentos eficientes para que esse processo se realizasse com sucesso. O subtítulo do relatório esclarece bem sua natureza: An evidence-based assessment of the scientific research literature on reading and its implications for reading instruction..$^{12} \mathrm{O}$ relatório conclui que, entre as facetas consideradas componentes essenciais do processo de alfabetização - consciência fonêmica, phonics $^{13}$ (relações fonema-grafema), fluência em leitura (oral e silenciosa), vocabulário e compreensão -, as evidências a que as pesquisas conduziam mostravam que têm implicações altamente positivas para a aprendizagem da língua escrita o desenvolvimento da consciência fonêmica e o ensino explícito, direto e sistemático das correspondências fonema-grafema.

Retomando o título deste subtópico, pode-se perguntar: nesse contexto - francês e norte-americano -

${ }^{12}$ Foge aos limites deste texto uma reflexão, no entanto necessária, sobre as estreitas relações entre pesquisa e ensino que se consolidaram nos Estados Unidos, particularmente em decorrência do No Child Left Behind Act, lei de 2001, que vinculou a concessão de recursos a escolas com problemas na área da alfabetização à fundamentação dos projetos em pesquisa quantitativa, experimental ou quase-experimental; sobre isso, pelo menos três aspectos mereceriam discussão: em primeiro lugar, o pressuposto de que resultados de pesquisa, sobretudo com alto grau de controle de variáveis, podem ser generalizados para toda e qualquer escola e sala de aula, para todo e qualquer professor, todo e qualquer grupo de alunos; em segundo lugar, o privilégio concedido à pesquisa quantitativa e experimental, em detrimento da pesquisa qualitativa e das abordagens etnográficas; em terceiro lugar, a exclusividade atribuída às evidências "científicas" como fundamento para o ensino, ignorando-se a contribuição das evidências decorrentes de práticas bem-sucedidas. Para a reflexão sobre essas questões, sugere-se a leitura de Cunningham (2001) e da "declaração de princípios" (position statement) da International Reading Association, What is evidence-based reading instruction? (IRA, 2002).

${ }^{13}$ Não há substantivo em português correspondente ao substantivo phonics da língua inglesa; isso tem levado à equivocada interpretação, no Brasil, de que phonics, na literatura de língua inglesa, traduz-se por método fônico de alfabetização. 
o que constitui a reinvenção da alfabetização? Uma análise tanto do documento francês - Apprendre à lire - quanto do relatório americano - o National Reading Panel - evidenciam que a concepção de aprendizagem da língua escrita, em ambos, é mais ampla e multifacetada que apenas a aprendizagem do código, das relações grafofônicas; o que ambos postulam é a necessidade de que essa faceta recupere a importância fundamental que tem na aprendizagem da língua escrita; sobretudo, que ela seja objeto de ensino direto, explícito, sistemático. Entretanto, a questão tem se colocado, particularmente nos Estados Unidos, e começa a se colocar assim também entre nós, em termos de antagonismo de concepções, uma oposição de grupos a favor e grupos contra o movimento que tem sido denominado a "volta ao fônico" (back to phonics) - como se, para endireitar a vara, fosse mesmo necessário curvá-la para o lado oposto, ou como se o pêndulo devesse estar ou de um lado, ou de outro. É essa tendência a radicalismos que torna perigosa a necessária reinvenção da alfabetização. ${ }^{14}$

O que é preciso reconhecer é que o antagonismo, que gera radicalismos, é mais político que propriamente conceitual, pois é óbvio que tanto a whole language, nos Estados Unidos, quanto o chamado construtivismo, no Brasil, consideram a aprendizagem das relações grafofônicas como parte integrante da aprendizagem da língua escrita - ocorreria a alguém a possibilidade de se ter acesso à cultura escrita sem a aprendizagem das relações entre o sistema fonológico e o sistema alfabético? A diferença entre propostas como a do Apprendre à lire ou do National Reading Panel, e propostas como a whole language e o construtivismo está em que, enquanto nas pri-

${ }^{14}$ Alguns exemplos do antagonismo entre phonics e whole language são: a coletânea de textos organizada por Kenneth Goodman (1998); a veemente crítica de Elaine Garan (2002) ao National Reading Panel; em posição oposta, a veemente crítica da whole language e defesa do National Reading Panel por Louisa Moats (2000). meiras considera-se que as relações entre o sistema fonológico e os sistemas alfabético e ortográfico devem ser objeto de instrução direta, explícita e sistemática, com certa autonomia em relação ao desenvolvimento de práticas de leitura e escrita, nas segundas considera-se que essas relações não constituem propriamente objeto de ensino, pois sua aprendizagem deve ser incidental, implícita, assistemática, no pressuposto de que a criança é capaz de descobrir por si mesma as relações fonema-grafema, em sua interação com material escrito e por meio de experiências com práticas de leitura e de escrita. Podese talvez dizer que, no primeiro caso, privilegia-se a alfabetização, no segundo caso, o letramento. $\mathrm{O}$ problema é que, num e noutro caso, dissocia-se equivocadamente alfabetização de letramento, e, no segundo caso, atua-se como se realmente pudesse ocorrer de forma incidental e natural a aprendizagem de objetos de conhecimento que são convencionais e, em parte significativa, arbitrários - o sistema alfabético e o sistema ortográfico.

Dissociar alfabetização e letramento é um equívoco porque, no quadro das atuais concepções psicológicas, lingüísticas e psicolingüísticas de leitura e escrita, a entrada da criança (e também do adulto analfabeto) no mundo da escrita ocorre simultaneamente por esses dois processos: pela aquisição do sistema convencional de escrita - a alfabetização - e pelo desenvolvimento de habilidades de uso desse sistema em atividades de leitura e escrita, nas práticas sociais que envolvem a língua escrita - o letramento. Não são processos independentes, mas interdependentes, e indissociáveis: a alfabetização desenvolvese no contexto de e por meio de práticas sociais de leitura e de escrita, isto é, através de atividades de letramento, e este, por sua vez, só se pode desenvolver no contexto da e por meio da aprendizagem das relações fonema-grafema, isto é, em dependência da alfabetização. A concepção "tradicional” de alfabetização, traduzida nos métodos analíticos ou sintéticos, tornava os dois processos independentes, a alfabetização - a aquisição do sistema convencional de escrita, o aprender a ler como decodificação e a es- 
crever como codificação - precedendo o letramento - o desenvolvimento de habilidades textuais de leitura e de escrita, o convívio com tipos e gêneros variados de textos e de portadores de textos, a compreensão das funções da escrita. Na concepção atual, a alfabetização não precede o letramento, os dois processos são simultâneos, o que talvez até permitisse optar por um ou outro termo, como sugere Emilia Ferreiro em recente entrevista à revista Nova Esco$l a,{ }^{15}$ em que rejeita a coexistência dos dois termos com o argumento de que em alfabetização estaria compreendido o conceito de letramento, ou vice-versa, em letramento estaria compreendido o conceito de alfabetização - o que seria verdade, desde que se convencionasse que por alfabetização seria possível entender muito mais que a aprendizagem grafofônica, conceito tradicionalmente atribuído a esse processo, ou que em letramento seria possível incluir a aprendizagem do sistema de escrita. A conveniência, porém, de conservar os dois termos parece-me estar em que, embora designem processos interdependentes, indissociáveis e simultâneos, são processos de natureza fundamentalmente diferente, envolvendo conhecimentos, habilidades e competências específicos, que implicam formas de aprendizagem diferenciadas e, conseqüentemente, procedimentos diferenciados de ensino. Sobretudo no momento atual, em que os equívocos e falsas inferências anteriormente mencionados levaram alfabetização e letramento a se confundirem, com prevalência deste último e perda de especificidade da primeira, o que se constitui como uma das causas do fracasso em alfabetização que hoje ainda se verifica nas escolas brasileiras, a distinção entre os dois processos e conseqüente recuperação da especificidade da alfabetização tornam-se metodologicamente e até politicamente convenientes, desde que essa distinção e a especificidade da alfabetização não sejam entendidas como independência de um processo em relação ao outro, ou como precedência de um em relação ao outro. Assegurados esses

${ }^{15}$ Ano XVIII, no 162, p. 30, maio 2003. pressupostos, a reinvenção da alfabetização revelase necessária, sem se tornar perigosa.

É que, diante dos precários resultados que vêm sendo obtidos, entre nós, na aprendizagem inicial da língua escrita, com sérios reflexos ao longo de todo o ensino fundamental, parece ser necessário rever os quadros referenciais e os processos de ensino que têm predominado em nossas salas de aula, e talvez reconhecer a possibilidade e mesmo a necessidade de estabelecer a distinção entre o que mais propriamente se denomina letramento, de que são muitas as facetas imersão das crianças na cultura escrita, participação em experiências variadas com a leitura e a escrita, conhecimento e interação com diferentes tipos e gêneros de material escrito - e o que é propriamente a alfabetização, de que também são muitas as facetas consciência fonológica e fonêmica, identificação das relações fonema-grafema, habilidades de codificação e decodificação da língua escrita, conhecimento e reconhecimento dos processos de tradução da forma sonora da fala para a forma gráfica da escrita. Por outro lado, o que não é contraditório, é preciso reconhecer a possibilidade e necessidade de promover a conciliação entre essas duas dimensões da aprendizagem da língua escrita, ${ }^{16}$ integrando alfabetização e letramento, sem perder, porém, a especificidade de cada um desses processos, o que implica reconhecer as muitas facetas de um e outro e, conseqüentemente, a diversidade de métodos e procedimentos para ensino de um e de outro, uma vez que, no quadro desta concepção, não há um método para a aprendizagem inicial da língua escrita, há múltiplos métodos, pois a natureza de cada faceta determina certos procedimentos de ensino, além de as características de cada grupo de crian-

${ }^{16}$ A busca de conciliação entre letramento - whole language e alfabetização - phonics - já vem sendo tentada nos Estados Unidos, com a sugestão de superação dos antagonismos pela opção por uma balanced instruction, que admite a compatibilidade entre as duas propostas e reconhece a possibilidade de sua coexistência (cf. Cowen, 2003; Blair-Larsen \& Williams, 1999; Freppon \& Dahl, 1998; Johnson, 1999). 
ças, e até de cada criança, exigir formas diferenciadas de ação pedagógica. ${ }^{17}$ Desnecessário se torna destacar, por óbvias, as conseqüências, nesse novo quadro referencial, para a formação de profissionais responsáveis pela aprendizagem inicial da língua escrita por crianças em processo de escolarização. ${ }^{18}$

Em síntese, o que se propõe é, em primeiro lugar, a necessidade de reconhecimento da especificidade da alfabetização, entendida como processo de aquisição e apropriação do sistema da escrita, alfabético e ortográfico; em segundo lugar, e como decorrência, a importância de que a alfabetização se desenvolva num contexto de letramento - entendido este, no que se refere à etapa inicial da aprendizagem da escrita, como a participação em eventos variados de leitura e de escrita, e o conseqüente desenvolvimento de habilidades de uso da leitura e da escrita nas práticas sociais que envolvem a língua escrita, e de atitudes positivas em relação a essas práticas; em terceiro lugar, o reconhecimento de que tanto a alfabetização quanto o letramento têm diferentes dimensões, ou facetas, a natureza de cada uma delas demanda uma metodologia diferente, de modo que a aprendizagem inicial da língua escrita exige múltiplas metodologias, algumas caracterizadas por ensino direto, explícito e sistemático - particularmente a alfabetização, em suas diferentes facetas - outras caracterizadas por ensino incidental, indireto e subordinado a possibilidades e

${ }^{17}$ A respeito da necessária multiplicidade de métodos para o ensino inicial da leitura e da escrita, é elucidativa a "declaração de princípios" (position statement) da International Reading Association, Using multiple methods of beginning reading instruction (IRA, 1999).

${ }^{18} \mathrm{O}$ que aqui se diz sobre a aprendizagem inicial da língua escrita por crianças em processo de escolarização também se aplica a adultos; a diferença está, fundamentalmente, na natureza das experiências e práticas de leitura e escrita proporcionadas a estes, e na necessária adequação do material escrito envolvido nessas experiências e práticas. Convém, assim, destacar a necessidade de uma formação para o responsável pela aprendizagem inicial da escrita por adultos tão específica e complexa quanto é a formação para o responsável pela aprendizagem inicial da escrita por crianças. motivações das crianças; em quarto lugar, a necessidade de rever e reformular a formação dos professores das séries iniciais do ensino fundamental, de modo a torná-los capazes de enfrentar o grave e reiterado fracasso escolar na aprendizagem inicial da língua escrita nas escolas brasileiras.

MAGDA SOARES, livre-docente em educação, é professora titular emérita da Faculdade de Educação da UFMG e pesquisadora do Centro de Alfabetização, Leitura e Escrita - CEALE, dessa Faculdade. Autora de vários artigos, capítulos de livros e livros sobre ensino da língua escrita, é também autora de coleções didáticas para o ensino de português, sendo a mais recente: Português - uma proposta para o letramento ( 8 volumes para o ensino fundamental, Editora Moderna). Publicações recentes sobre o tema do artigo: Letramento: um tema em três gêneros (Autêntica, 1996) e Alfabetização e letramento (Contexto, 2003), os capítulos de livros "Letramento e escolarização" (no livro Letramento no Brasil, organizado por Vera Masagão Ribeiro, Global, 2003), “Aprender a escrever, ensinar a escrever" (no livro A magia da linguagem, organizado por Edwiges Zaccur, DP\&A, 1999), “A escolarização da literatura infantil e juvenil" (no livro A escolarização da leitura literária, organizado por Aracy Alves Martins Evangelista et al., Autêntica, 1999), o documento Alfabetização, em co-autoria com Francisca Maciel, produto de pesquisa sobre o estado do conhecimento a respeito da alfabetização, no Brasil (publicação MEC/INEP/COMPED, 2001, na série Estado do Conhecimento). Organizou o dossiê sobre letramento, publicado no periódico Educação e Sociedade, nº 81, dezembro de 2002. E-mail: mbecker.soares@terra.com.br

\section{Referências bibliográficas}

ADAMS, Marylin Jager, (1990). Beginning to read: thinking and learning about print. Cambridge, MA: MIT Press.

ANDERSON, Richard C., HIEBERT, Elfrieda H., SCOTT, Judith A., WILKINSON, Ian A.G., (1985). Becoming a nation of readers: the report of the Commission on Reading. Washington, DC: National Institute of Education.

BARTON, David, (1994). Literacy: an introduction to the ecology of written language. Oxford, UK: Blackwell.

BLAIR-LARSEN, Susan M., WILLIAMS, Kathryn A. (eds.), (1999). The balanced reading program: helping all students achieve success. Newark, DE: International Reading Association. 
BOND, Guy L., DYKSTRA, Robert, (1967/1997). The cooperative research program in first-grade reading instruction. Reading Research Quarterly, v. 32, n 4, p. 345-427.

CHALL, Jeanne S., (1967). Learning to read: the great debate. New York: McGraw Hill.

CHARTIER, Anne-Marie, HÉBRARD, Jean, (2000). Discours sur la lecture - 1880-2000. $2^{\mathrm{a}}$ ed. Paris: Centre Pompidou; Fayard. COWEN, John Edwin, (2003). A balanced approach to beginning reading instruction: a synthesis of six major U.S. research studies. Newark, DE: International Reading Association.

CUNNINGHAM, James W., (2001). The National Reading Panel Report. Reading Research Quarterly, v. 36, nº 3, p. 326-335.

FERREIRO, Emilia, TEBEROSKY, Ana, (1985). Psicogênese da língua escrita. Porto Alegre: Artes Médicas. Tradução de D. M. Lichtenstein, L. Di Marco, M. Corso.

FREPPON, Penny A., DAHL, Karin L., (1998). Balanced instruction: insights and considerations. Reading Research Quarterly, v. 33, n² 2, p. 240-251.

GAFFNEY, Janet S., ANDERSON, Richard C., (2000). Trends in reading research in the United States: changing intellectual currents over three decades. In: KAMIL, M. L., MOSENTHAL, P. B., PEARSON, P. D., BARR, R. Handbook of reading research - v. III. Mahwah, NJ: Lawrence Erlbaum, p. 53-74.

GARAN, Elaine M., (2002). Resisting reading mandates: how to triumph with the truth. Portsmouth, NH: Heinemann.

GOODMAN, Kenneth S. (ed.), (1998). In defense of good teaching: what teachers need to know about the "reading wars". York, Maine: Stenhouse Publishers.

IRA - International Reading Association, (1999). Using multiple methods of beginning reading instruction. A position statement. January, 1999. Disponível em: <www.reading.org/pdf/ methods.pdf>. Acesso em: 10 de julho de 2003.

, (2002). What is evidence-based reading instruction?

A position statement. May, 2002. Disponível em: <www.reading.org/pdf/1055.pdf> (Também reproduzido no livro: Evidence-based reading instruction: putting the National Reading Panel Report into practice. Newark, DE: International Reading Association, p. 232-236.).

JOHNSON, Debra, (1999). Balanced reading instruction: review of literature. North Central Regional Educational Laboratory (NCREL), on-line. Disponível em: <www.ncrel.org/sdrs/ timely/briiss.htm>. Acesso em: 1 set. 2003.

KIRSCH, Irwin S., JUNGEBLUT, Ann, (1986). Literacy: profiles of America's young adults. Final report of the National
Assessment for Educational Progress. Princeton: N.J.: Educational Testing Service.

KLEIMAN, Ângela (org.), (1995). Os significados do letramento. Campinas: Mercado de Letras.

LAHIRE, Bernard, (1999). L'invention de l' "illettrisme”: rhétorique publique, éthique et stigmates. Paris: La Découverte.

MOATS, Louisa Cook, (2000). Whole language lives on: the illusion of "balanced" reading instruction. The Thomas B. Fordham Foundation. Disponível em: <www.edexcellence.net/ library/wholelang/moats.html>. Acesso em: 14 set. 2003.

NATIONAL INSTITUTE OF CHILD HEALTH AND HUMAN DEVELOPMENT - NICHD, (2000). Report of the National Reading Panel: teaching children to read: an evidence-based assessment of the scientific research literature on reading and its implications for reading instruction. Washington, DC: U.S. Government Printing Office.

OBSERVATOIRE NATIONAL DE LA LECTURE. Ministère de l'Éducation Nationale de la Recherche et de la Technologie, (1998). Apprendre à lire au cycle des apprentissages fondamentaux: analyses, réflexions et propositions. Paris: Éditons Odile Jacob.

ROJO, Roxane (org.), (1998). Alfabetização e letramento. Campinas: Mercado de Letras.

SMITH, E. Brooks, GOODMAN, Kenneth S., MEREDITH, Robert, (1970). Language and thinking in school. New York: Holt, Rinehart and Winston.

SMITH, Frank, (1973). Psycholinguistics and reading. New York: Holt, Rinehart and Winston. , (1997). Reading without nonsense. New York: Teachers College Press.

SNOW, Catherine E., BURNS, Susan, GRIFFIN, Peg (eds.), (1998). Preventing reading difficulties in young children. Washington, DC: National Academy Press.

SOARES, Magda Becker, (1998). Letramento: um tema em três gêneros. Belo Horizonte: Autêntica.

, (2003). Alfabetização: a ressignificação do conceito. Alfabetização e Cidadania, nº 16, p 9-17, jul.

SOARES, Magda Becker, MACIEL, Francisca, (2000). Alfabetização. Brasília: MEC/INEP/COMPED (série Estado do Conhecimento). TFOUNI, Leda Verdiani, (1988). Adultos não alfabetizados: o avesso do avesso. Campinas: Pontes.

, (1995). Letramento e alfabetização. São Paulo: Cortez.

Recebido e aprovado em outubro de 2003 